\title{
Influence of Pin Length and Electrochemical Platings on the Mechanical Strength and Macroscopic Defect Formation in Stationary Shoulder Friction Stir Welding of Aluminium to Copper
}

\author{
Anna Regensburg ${ }^{1, *}$, René Schürer ${ }^{1}$, Markus Weigl ${ }^{2}$ and Jean Pierre Bergmann ${ }^{1}$ \\ 1 Department of Production Technology, Technische Universität Ilmenau, 98693 Ilmenau, Germany; \\ rene.schuerer@tu-ilmenau.de (R.S.); jeanpierre.bergmann@tu-ilmenau.de (J.P.B.) \\ 2 Grenzebach Maschinenbau GmbH, 86663 Asbach-Bäumenheim, Germany; markus.weigl@grenzebach.com \\ * Correspondence: info.fertigungstechnik@tu-ilmenau.de
}

Received: 6 December 2017; Accepted: 23 January 2018; Published: 24 January 2018

\begin{abstract}
The fabrication of dissimilar joints for electrical applications raises challenges for conventional joining technologies. Within solid-state processes, friction stir welding (FSW) provides numerous advantages to realize different joint configurations. However, depending on the intermixing of the materials, defects like hooking and significant intermetallic compound formation around copper fragments are observed and lead to a decrease in joint properties. Therefore, stationary shoulder FSW was applied to produce $2 \mathrm{~mm}$ EN AW1050/CW024A lap joints with minimized intermixing at the interface. Compared to conventional FSW, the range of the friction-based heat input can be increased without risking excessive plastification under the tool shoulder. The influence of the pin length on the interfacial structure as well as the mechanical properties were investigated. A pin length of $2.2 \mathrm{~mm}$ and hence a plunging of approximately $0.2 \mathrm{~mm}$ into the lower copper sheet was found to obtain the highest failure load. A further increase caused the formation of hooking defects, which led to void formation at the interface and failure within the area of the thinned aluminium sheet. The results were also transferred to lap joints with a tin and silver interlayer of $10 \mu \mathrm{m}$ and also showed good results in terms of bond strength and contact area.
\end{abstract}

Keywords: friction stir welding; aluminium; copper; dissimilar joints; lap joints

\section{Introduction}

The substitution of copper by aluminium is widely pursued in order to save weight and material costs, especially in automotive battery applications. However, the tendency of aluminium towards creep and the natural oxide layer can present drawbacks for force lock connections. As a consequence, the substitution is usually not carried out completely, and components with high requirements in strength and loadability under elevated temperature are still made from copper. Therefore, various applications require the joining of dissimilar joints without deteriorating the electrical and mechanical properties at the interface. In solid state welding, the fabrication of dissimilar joints between aluminium and copper has been the subject of various investigations [1-3]. In order to ensure good electrical properties of the dissimilar joints, the objective of available welding technologies is to obtain a high bond strength combined with maximum contact area. In this way, the contact resistance at the interface can be kept minimal. However, the formation of intermetallic compounds (IMCs) at high process temperature or high total heat input has to be considered as well. Typical intermetallic compounds form between $200-500{ }^{\circ} \mathrm{C}$, and can exhibit hardness and electrical resistance values which are significantly higher than those of the base materials [4-6]. Apart from that, the presence of electrical current and elevated operating temperatures (e.g., in batteries) leads to further phase growth [7] and possible 
deterioration of the electrical and mechanical properties [8]. The formation of the specific IMCs between $\mathrm{Al}-\mathrm{Cu}$ is not directly comparable to, for example, the case of $\mathrm{Fe}-\mathrm{Al}$ or $\mathrm{Fe}-\mathrm{Mg}$, but is indeed very similar [9-11]. The extension and the morphology of IMC depend on the diffusion of the elements to each other, the dilution, the maximum temperature and on the cooling regime. In the case of $\mathrm{Fe}-\mathrm{Al}$, the diffusion of $\mathrm{Fe}$ in $\mathrm{Al}$ is much higher than vice versa [12], so IMC are very difficult to avoid; the diffusion of $\mathrm{Cu}$ in $\mathrm{Al}$ and vice versa leads to a comparable layer thickness in both metals, at least under technical conditions and for temperatures lower than the liquidus temperature [13].

When fusion welding of aluminium with copper is performed, IMCs will form out of the common weld pool during cooling and solidification. Different approaches in order to join aluminium and copper-especially via laser welding — are presented in the literature. While Weigl et al. [14] and Gillner et al. [15] used process variations like adapted filler wire or high brilliance laser, respectively, Fetzer et al. [16] obtained a reduced weld penetration of the upper copper sheet in lap joints by beam oscillation. Schmalen et al. [17] presented a modified laser brazing process with a pulsed laser equipment, where the lower copper sheet remains solid and the resultant IMC formation can be reduced to avoid significant interface embrittlement.

In order to minimize the peak temperature and the heat input during joining, solid state welding technologies offer promising process variations for obtaining the required interface properties. By applying processes like electromagnetic pulse welding [18], ultrasonic welding [19,20], and friction stir welding [21], the IMC formation can be minimized successfully. Friction welding and friction stir welding, which can be defined as heat and forge type processes as described by Gould [22], are especially suitable for dissimilar joints, as the high applied strain under elevated temperature allows the displacement of oxides and containments and rapid bond formation in solid state by recrystallization.

In order to join compact or rotationally symmetric work pieces, Wanjara et al. [23] and Wei et al. [24] as well as Lee et al. [25] showed the good applicability of linear friction welding and continuous drive friction welding for Al-Cu joints, respectively. Dependent on the process control, IMC formation can be minimized to a total thickness of maximum 5-10 $\mu \mathrm{m}$. Bhamji et al. [26] even reached $0.7 \mu \mathrm{m}$ in sound welds, presumably by reaching the eutectic temperature and pressing out the formed composite melt between solid $\mathrm{Al}$ and $\mathrm{Cu}$.

Friction stir welding on the other hand has gained significant importance for sheet metal connections, both in butt and lap joint configuration. In butt joints, the lateral offset of the tool has a significant influence on the weld formation. In order to counteract the difference in flow stress and melting temperature between the two materials, the tool is usually shifted towards the aluminium. Xue et al. [27] recommend that no active stirring between $\mathrm{Al}$ and $\mathrm{Cu}$ takes places, only leaving a small diffusion layer of approximately $3 \mu \mathrm{m}$ which contributes to the joint strength. Otherwise, large copper particles and fragments are pulled into the stirring zone, which results in significant void and IMC formation. Hence, only minor failure loads can be obtained, as the interface reaction results in brittle failure of the joints.

For lap joints, apart from the general tool design, the positioning of the work pieces and the penetration depth of the tool into the lower sheet are considered important factors. Galvao et al. [28] observed increased intermixing, IMC formation and void formation for lap joints of pure copper and EN AW5083/AW6082, respectively, when copper is directly processed by the tool shoulder. Investigations of Akbari et al. [29] showed an up to $26 \%$ increased peak temperature in this configuration. In terms of heat and wear minimization, most investigations are therefore carried out with aluminium as the top sheet. In this case, the penetration of the pin tip into the lower copper sheet determines the heat input at the interface, as the active stirring of copper leads to higher peak temperatures and the formation of the so-called hooking defect [30]. This effect is caused by the material of the lower sheet being pulled into the top sheet by the pin. The temperature of this extruded material can cause significant softening of the adjacent aluminium and usually results in pronounced void and/or IMC formation [31,32]. Consequently, the bonding between the sheets should rather 
be obtained by an increased frictional heat input at the interface instead of by increased plunging into the copper sheet. However, as the major part of plastification and material flow occurs right under shoulder surface, the variation of the process parameters towards a higher heat input at the lap interface is limited by possible flash formation due to excessive plastification at the outer edge of the tool shoulder. As a possible solution, the application of the stationary shoulder concept [33] enables the shift towards a rather pin-dominated material flow and the fabrication of welds with significantly reduced weld volume at full penetration depth [34]. As the maximum trajectory speed occurs at the pin surface, the tool shoulder only contributes a forging effect, leading to a decreased sensitivity towards excessive surface plastification, while the pressure on the stir zone is kept constant.

Therefore, the objective of this investigation is to obtain sound Al-Cu lap joints with high mechanical properties and minimized hooking formation and intermixing at the interface by applying the stationary shoulder concept. Compared to conventional friction stir welding (FSW), the material under the shoulder is plasticized less, which avoids excessive flash formation and plunging. Consequently, higher rotational speeds can be applied without causing surface defects. In this way, the friction-based heat input at the interface and the pin tip can be increased so that the joint formation takes place due to diffusion-based mechanisms instead of pronounced intermixing and interlocking.

\section{Experimental Procedure}

Figure 1 shows the used process setup; $2 \mathrm{~mm}$ EN AW1050 H14 and $2 \mathrm{~mm}$ EN CW024A R240 sheets with a total width of $50 \mathrm{~mm}$ and a length of $250 \mathrm{~mm}$ were welded in lap configuration with a lap width of $50 \mathrm{~mm}$. A stationary shoulder tool system by Grenzebach Maschinenbau GmbH (Asbach-Bäumenheim, Germany) was applied for the experiments. The shoulder, pin root, and tip diameter were $10 \mathrm{~mm}, 5 \mathrm{~mm}$, and $3 \mathrm{~mm}$, respectively. The pin length was varied between $1.8 \mathrm{~mm}$ and $2.6 \mathrm{~mm}$ in steps of $0.2 \mathrm{~mm}$. The experiments were carried out on a force-controlled robotic FSW system by Grenzebach Maschinenbau GmbH (Asbach-Bäumenheim, Germany) employed with a heavy-duty robot KUKA KR5000 and a specially designed spindle for rotational speeds up to 14,000 rpm.
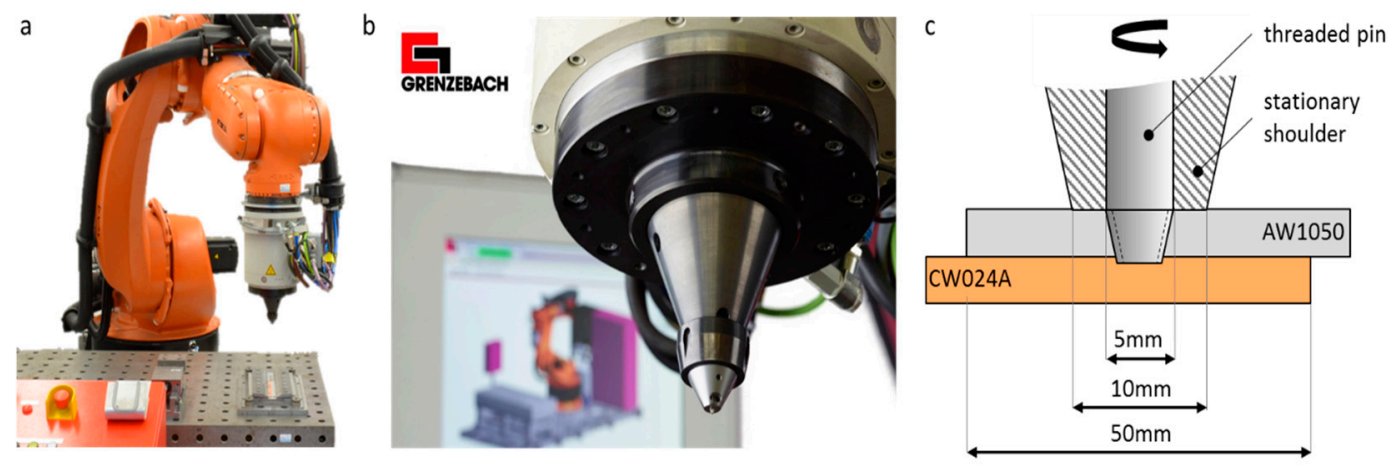

Figure 1. Process setup: (a) Robotic friction stir welding (FSW) system (Grenzebach); (b) Stationary shoulder tool; (c) Schematic illustration of the tool and joint configuration.

According to preliminary experiments, the rotational speed, welding speed, and welding force were set to constant values of $5000 \mathrm{rpm}, 750 \mathrm{~mm} / \mathrm{min}$, and $3 \mathrm{kN}$, respectively, in order to analyse the influence of the varying pin length. In addition to the direct $\mathrm{Al} / \mathrm{Cu}$ joints, the experiments were carried out with $10 \mu \mathrm{m}$ tin- and silver-plated copper plates in order to evaluate the behaviour of the interlayers during welding. Three tensile specimens with an overall length of $95 \mathrm{~mm}$ and a gage width of $12 \mathrm{~mm}$ were cut out of each weld and subjected to tensile testing with a testing speed of $10 \mathrm{~mm} / \mathrm{min}$. Furthermore, metallographical preparation of cross- and longitudinal sections was carried out as well as on selected failed samples. 


\section{Results and Discussion}

Figure 2 shows the weld surface of the lap joints. Welds with different pin lengths or platings show no differences in the surface quality. This effect is contributed by the stationary shoulder, which avoids the typical flash formation and surface structure by basically sliding over the work piece surface.

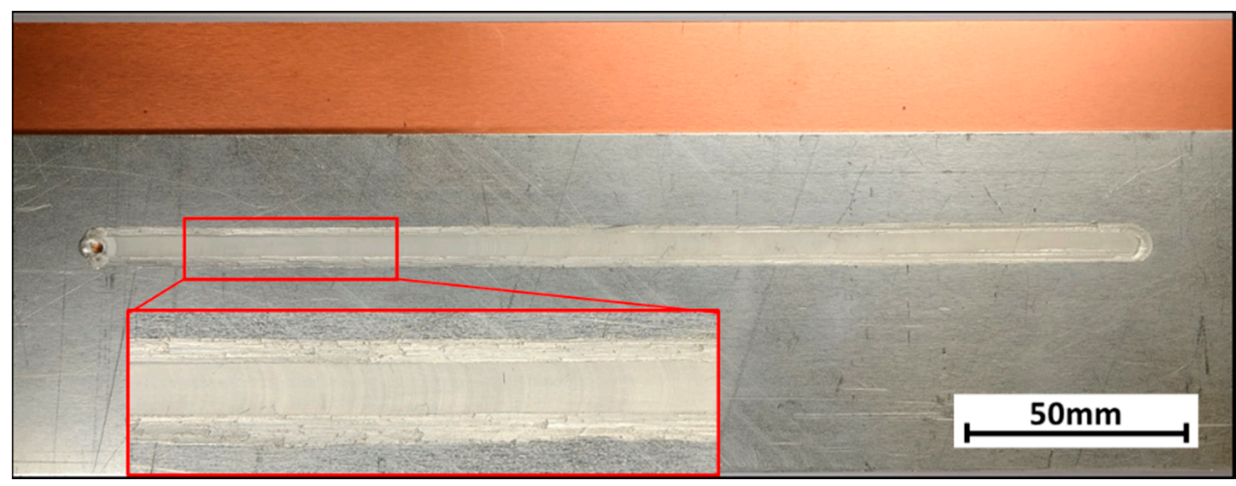

Figure 2. Illustration of the sample geometry.

However, the influence of the pin length can be observed in the cross-sections in Figures 3 and 4. For further considerations, it has to be noted that due to the force-controlled FSW system and the constant axial force of $3 \mathrm{kN}$, the increase in pin length does not equal the same increase in penetration depth. However, the shoulder does not lose contact with the work piece surface in any parameter.
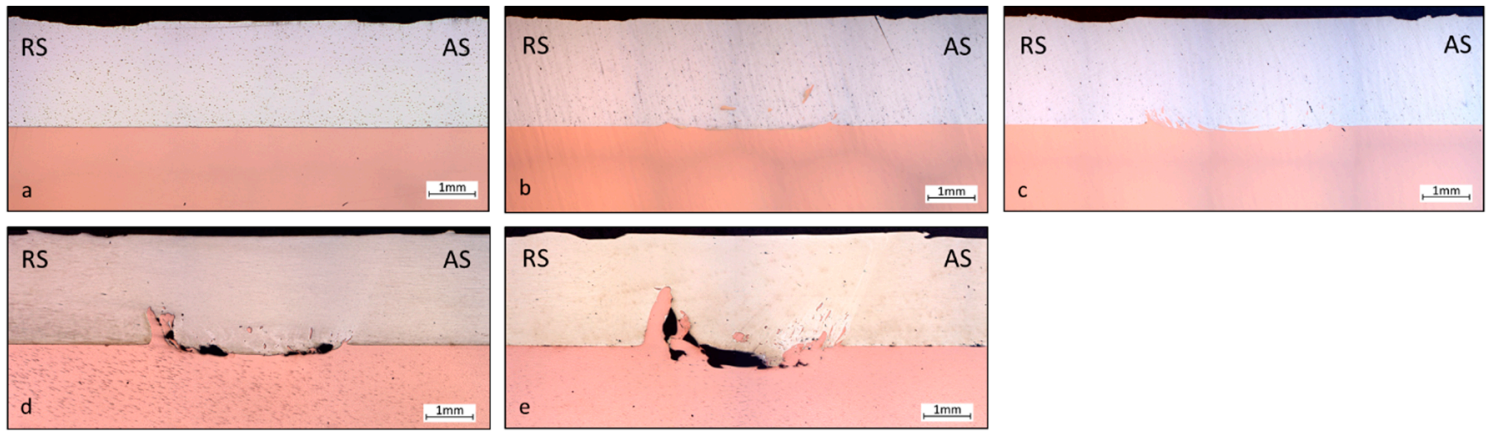

Figure 3. Influence of the pin length on the interface structure: (a) $1.8 \mathrm{~mm}$; (b) $2.0 \mathrm{~mm}$; (c) $2.2 \mathrm{~mm}$; (d) $2.4 \mathrm{~mm}$ and (e) $2.6 \mathrm{~mm}$. AS: Advancing Side, RS: Retreating Side.
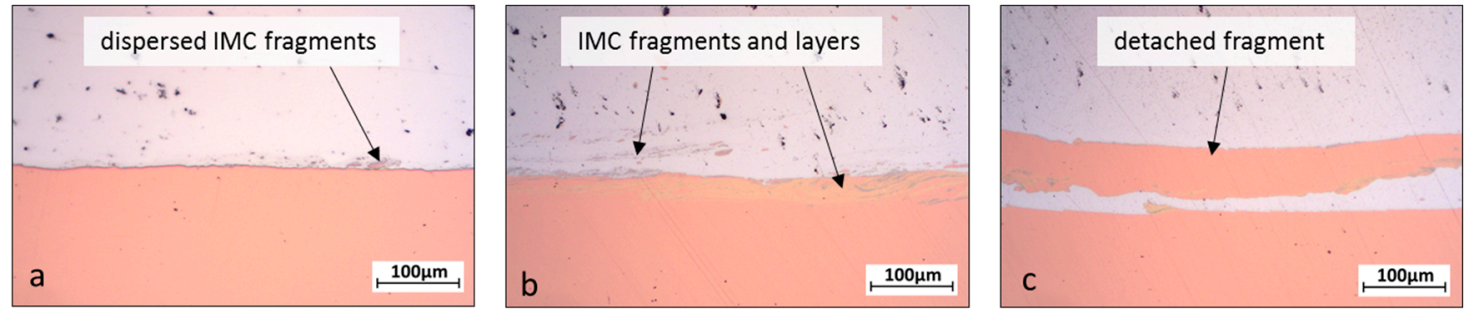

Figure 4. Detailed view of the centre of the interface at (a) $1.8 \mathrm{~mm}$; (b) $2.0 \mathrm{~mm}$; and (c) $2.2 \mathrm{~mm}$. IMC: intermetallic compound.

While a pin length of $1.8 \mathrm{~mm}$ leads to no interface deformation, an imprint of the pin tip can be observed for $2.0 \mathrm{~mm}$ and $2.2 \mathrm{~mm}$. In this area, small copper fragments are detached from the lower sheet, but still form a sound weld. In the detailed view in Figure 4, intermetallic compound formation can also be observed within the actively stirred area, even at low penetration of the copper sheet 
(see Figure 4a). However, the phase layers are dispersed and irregular, which can be beneficial for the joint properties in terms of electrical conductivity and crack propagation.

At a pin length of $2.2 \mathrm{~mm}$ and $2.4 \mathrm{~mm}$, significant hook formation can be observed at the retreating side. When large areas of copper are actively deformed and extruded around the pin, the temperatures at the interfaces are assumed to increase significantly, so that aluminium in this area is much more softened than, for example, under the tool shoulder. Hence, the coefficient of friction decreases and possible sliding effects lead to an interruption of the material flow and resultant void formation.

Figure 5 shows the periodicity of the hooking defect and other microstructural effects in the longitudinal sections. While the intermixing is minimized at $1.8 \mathrm{~mm}$, the extrusion of single copper fragments can be observed at $2 \mathrm{~mm}$ pin length. These fragments show a typical layer structure, which has repeatedly been observed in $\mathrm{Al} / \mathrm{Cu}$ joints and identified as mostly intermetallic compounds [28-30]. It can be assumed that the pronounced IMC formation occurs when fragments are detached from the copper base material and are transported around the pin, presumably for numerous revolutions. This leads to severe plastic deformation of the copper within the plasticized aluminium. Hence, the forging effect is promoted and diffusion between the materials is highly facilitated. As the evolution of the hooking effect increased with increasing pin length of 2.2-2.6 mm, a sawtooth-like structure developed at the copper side. It consisted of the material being displaced behind the pin during the traverse motion of the tool. In contrast to the detached copper fragments, only minor IMC formation could be observed in this area, as the copper was not extruded various times around the tool. Furthermore, a continuous void formation could be observed at the interface for a pin length of $2.4 \mathrm{~mm}$ and $2.6 \mathrm{~mm}$, as already seen in the cross-sections and is mainly assumed to be caused by the hooking defect.
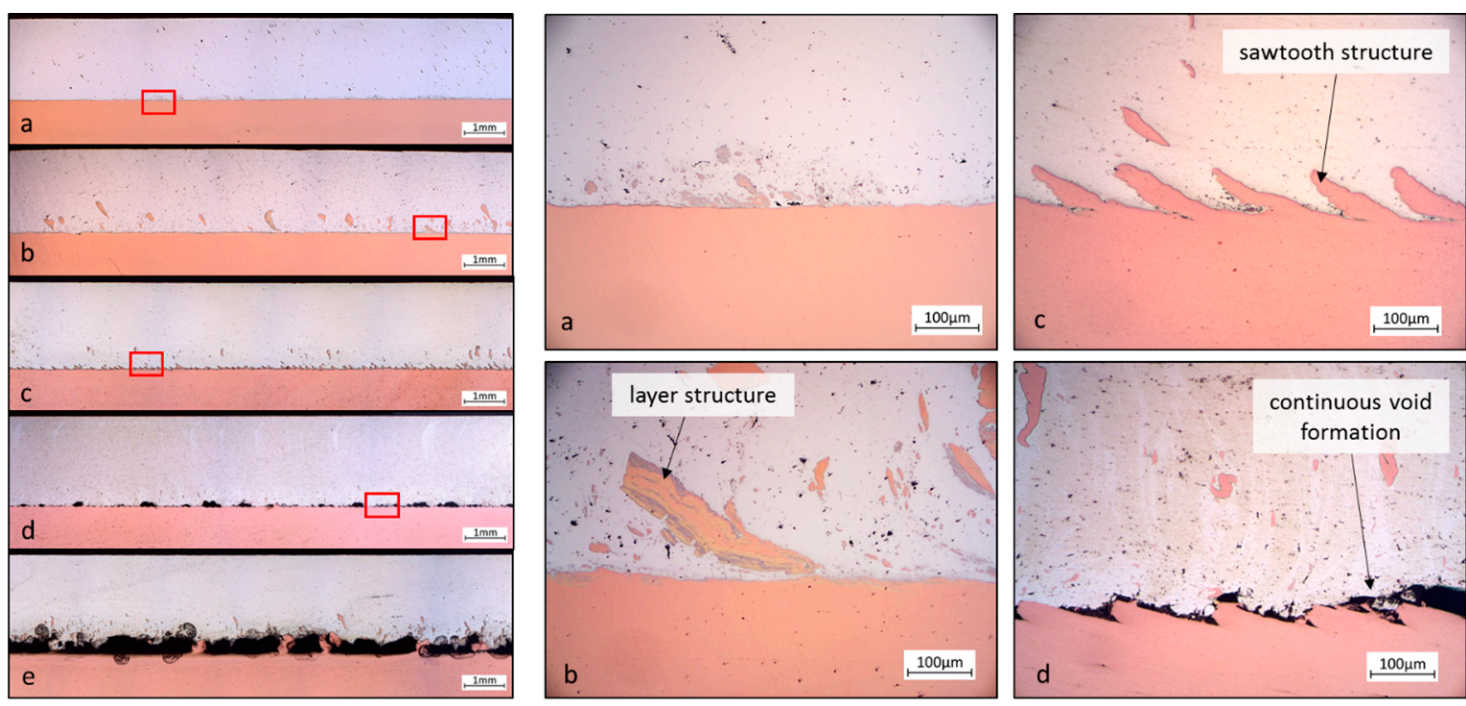

Figure 5. Influence of the pin length on the longitudinal weld structure: (a) $1.8 \mathrm{~mm}$; (b) $2.0 \mathrm{~mm}$; (c) $2.2 \mathrm{~mm}$; (d) $2.4 \mathrm{~mm}$; and (e) $2.6 \mathrm{~mm}$.

However, it must also be considered that the increased plunging of the pin into the copper material at constant process force might lead to less pressure under the shoulder and a slightly reduced forging effect. This interaction between the increased material resistance at increased pin length and the force-dependent plunging depth might also contribute to the defect formation at $2.4 \mathrm{~mm}$ and $2.6 \mathrm{~mm}$ pin length. For these two values, a slight deviation of maximum $0.1 \mathrm{~mm}$ could be measured in the cross-section. However, no change of the plunging depth was recorded over the weld length.

The hooking also showed a significant influence on the weld strength, as shown in Figure 6. At a pin length of $2.0 \mathrm{~mm}$ and $2.2 \mathrm{~mm}$, when little hook formation occurred, the welds reached values close to the tensile load of the aluminium base material and consequently show a failure behaviour with a 
significant deformation of the aluminium sheet as shown in Figure 7. At $2.4 \mathrm{~mm}$ and $2.6 \mathrm{~mm}$ pin length, the failure load decreased by up to $28 \%$. This effect can be attributed to the reduced cross-section of the aluminium sheet as well as the little bonding at the averted side of the copper hook.

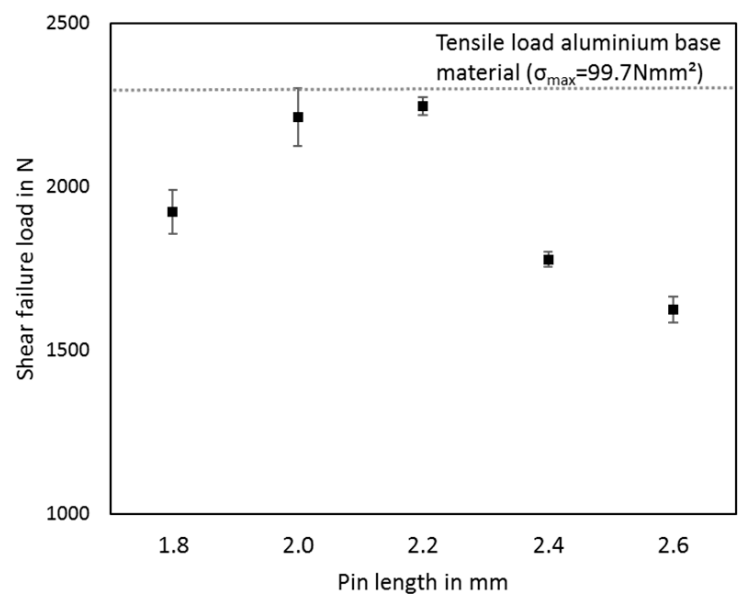

Figure 6. Influence of the pin length on the shear failure load.

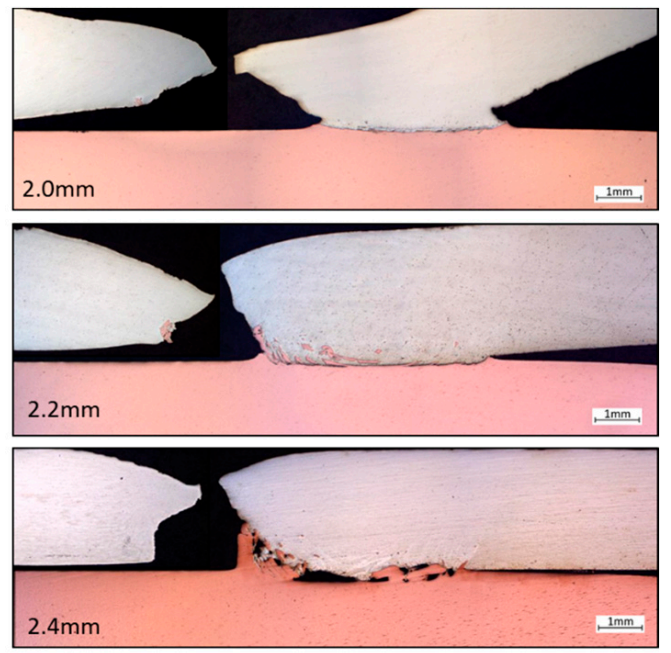

Figure 7. Influence of the pin length on the failure behaviour.

As electrochemical platings are often applied as diffusion barriers and protection against galvanic corrosion, the influence of $10 \mu \mathrm{m}$-thick silver and tin plating was investigated as well. As shown in Figure 8 at a pin length of $1.8 \mathrm{~mm}$ and $2.2 \mathrm{~mm}$, the resultant shear failure load remained in a relative constant range, especially at increased penetration depth. Due to the lower hardness of both platings, the material is assumed to be displaced from the stirring area at a penetration of the lower sheet. Figure 8 also shows detailed views of the Ag-plated interface with $2.2 \mathrm{~mm}$ pin length in the longitudinal section (centre of the weld). In this case, the soft plating was mostly displaced out of the stirring zone, leading to a direct joint of aluminium and copper without significant intermixing with the plating. Apart from the advantages for the joint quality, this effect can also offer a sealing effect and hence a protection of the direct joint interface against the entry of corrosive media. The displacement of the softened material can also be observed in the SEM images in Figure 9a, whereas the Sn plating was almost completely displaced from the stirring area while the Ag plating still left some layers attached to larger $\mathrm{Cu}$ particles. 

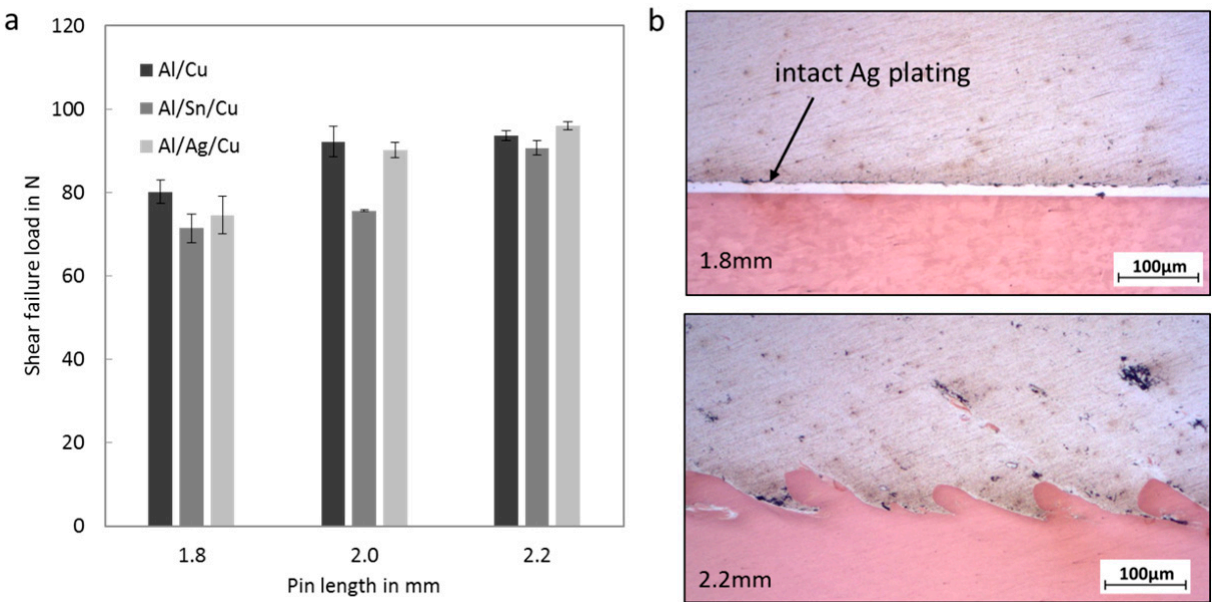

Figure 8. Influence of the plating on (a) the resultant failure load at $1.8 \mathrm{~mm}$ and $2.2 \mathrm{~mm}$ pin length; (b) detailed view on the longitudinal section of joints with Ag plated copper sheets.
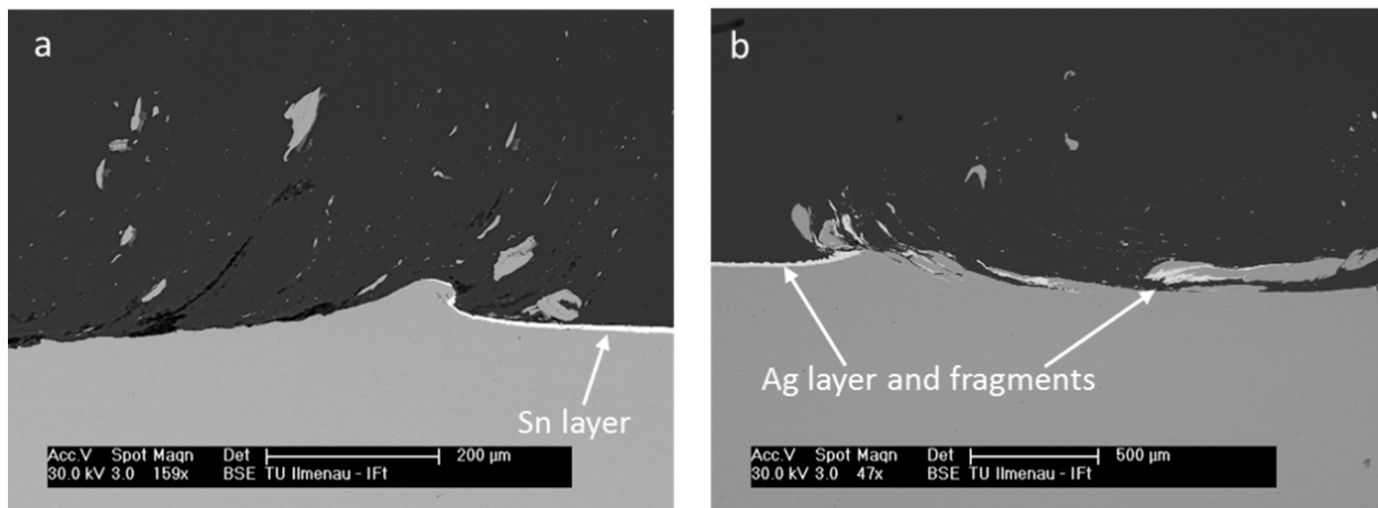

Figure 9. Displacement of the interface plating at $2.2 \mathrm{~mm}$ pin length at the boundary of the stirring area: (a) Sn; (b) Ag.

\section{Summary and Conclusions}

Lap joints between aluminium and copper were produced by stationary shoulder friction welding, which allows the application of high rotational speeds due to less frictional heat input in the area close to the tool shoulder. Hence, the heat input at the interface can be increased without excessive flash formation at the weld surface. The influence of the pin length on the joint properties at otherwise constant parameters was investigated. It was shown that sound welds with a failure of the samples in the aluminium base material can be produced at minimum penetration of the copper sheet of approximately $0.1 \mathrm{~mm}$ at a relatively high rotational speed of $5000 \mathrm{rpm}$, a process force of $3 \mathrm{kN}$, and a welding speed of $750 \mathrm{~mm} / \mathrm{min}$. In this way, the intermixing between the materials and the detachment of large copper fragments is minimized, leading to very minor IMC formation at the interface. Hence the IMCs do not have a direct influence on the static mechanical properties. The morphology of the formed IMCs and their influence on further joint properties will be a topic of further investigations.

An increase in pin length towards more than $2.2 \mathrm{~mm}$ causes more copper to be plasticized and being pulled into the top sheet, so that macroscopic hooking defects and significant void formation in adjacent areas can be observed. Due to the reduced cross-section of the aluminium sheet, the achievable failure load was then reduced by up to $28 \%$. The results can also be transferred to electrochemically plated sheets, where a displacement of $10 \mu \mathrm{m}$ interlayers was obtained at the boundary of the stir zone, leading to failure loads and failure behaviour comparable to those of the plain $\mathrm{Al}-\mathrm{Cu}$ joint. 
Acknowledgments: We acknowledge support for the Article Processing Charge by the German Research Foundation and the Open Access Publication Fund of the Technische Universität Ilmenau.

Author Contributions: Anna Regensburg., René Schürer, Markus Weigl and Jean Pierre Bergmann conceived and designed the experiments; Anna Regensburg and René Schürer performed the experiments and analyzed the data; Markus Weigl contributed materials and technical support; Anna Regensburg and Jean Pierre Bergmann wrote the paper.

Conflicts of Interest: The authors declare no conflict of interest.

\section{References}

1. Kah, P.; Vimalraj, C.; Martikainen, J.; Suoranta, R. Factors influencing Al-Cu weld properties by intermetallic compound formation. Int. J. Mech. Mater. Eng. 2015, 10, 1-13. [CrossRef]

2. Mehta, K.P.; Badheka, V.J. A Review on Dissimilar Friction Stir Welding of Copper to Aluminum: Process, Properties, and Variants. Mater. Manuf. Process. 2016, 31, 233-254. [CrossRef]

3. Lee, S.S.; Kim, T.H.; Hu, S.J.; Cai, W.W.; Abell, J.A. Joining Technologies for Automotive Lithium-Ion Battery Manufacturing: A Review. In Proceedings of the ASME 2010 International Manufacturing Science and Engineering Conference, Erie, PA, USA, 12-15 October 2010.

4. Pelzer, R.; Woehlert, S.; Koerner, H.; Khatibi, G.; Walter, J. Growth behavior and physical response of Al-Cu intermetallic compounds. In Proceedings of the 2014 IEEE 16th Electronics Packaging Technology Conference (EPTC), Singapore, 3-5 December 2014; pp. 372-377.

5. Pfeifer, S. Einfluss Intermetallischer Phasen der Systeme Al-Cu und Al-Ag Auf Den Widerstand Stromtragender Verbindungen im Temperaturbereich Von $90^{\circ} \mathrm{C}$ Bis $200^{\circ} \mathrm{C}$; Technische Universität Dresden: Dresden, Germany, 2015.

6. Guo, Y.; Liu, G.; Jin, H.; Shi, Z.; Qiao, G. Intermetallic phase formation in diffusion-bonded Cu/ Al laminates. J. Mater. Sci. 2011, 46, 2467-2473. [CrossRef]

7. Braunovic, M.; Aleksandrov, N. Intermetallic Compounds at Aluminium-to-Copper Electrical Interfaces: Effect of Temperature and Electric Current. IEEE Trans. Compon. Packag. Manuf. Technol. Part A 1994, 17, 78-85. [CrossRef]

8. Abbasi, M.; Karimi Taheri, A.; Salehi, M.T. Growth rate of intermetallic compounds in Al/Cu bimetal produced by cold roll welding process. J. Alloys Compd. 2001, 319, 233-241. [CrossRef]

9. Casalino, G.; Guglielmi, P.; Lorusso, V.D.; Mortello, M.; Peyre, P.; Sorgente, D. Laser offset welding of AZ31B magnesium alloy to 316 stainless steel. J. Mater. Process. Technol. 2017, 242, 49-59. [CrossRef]

10. Casalino, G.; Mortello, M.; Peyre, P. Yb-YAG laser offset welding of AA5754 and T40 butt joint. J. Mater. Process. Technol. 2015, 223, 139-149. [CrossRef]

11. Casalino, G.; Leo, P.; Mortello, M.; Perulli, P.; Varone, A. Effects of Laser Offset and Hybrid Welding on Microstructure and IMC in Fe-Al Dissimilar Welding. Metals 2017, 7, 282. [CrossRef]

12. Rathod, M.J.; Kutsuna, M. Joining of Aluminum Alloy 5052 and Low-Carbon Steel by Laser Roll Welding. Weld. Int. 2010, 20, 446-456.

13. Bergmann, J.P.; Petzoldt, F.; Schürer, R.; Schneider, S. Solid-state welding of aluminum to copper-Case studies. Weld. World 2013, 57, 541-550. [CrossRef]

14. Weigl, M.; Albert, F.; Schmidt, M. Enhancing the Ductility of Laser-Welded Copper-Aluminum Connections by using Adapted Filler Materials. Phys. Procedia 2011, 12, 332-338. [CrossRef]

15. Gillner, A. Laserstrahlmikroschweißen Mit Faserlasern und Innovativen Verfahrenskonzepten; Laseranwenderforum: Bremen, Germany, 2006.

16. Fetzer, F.; Jarwitz, M.; Stritt, P.; Weber, R.; Graf, T. Fine-tuned Remote Laser Welding of Aluminum to Copper with Local Beam Oscillation. Phys. Procedia 2016, 83, 455-462. [CrossRef]

17. Schmalen, P.; Plapper, P. Evaluation of laser braze-welded dissimilar Al-Cu joints. Phys. Procedia 2016, 83, 506-514. [CrossRef]

18. Marya, M.; Marya, S.; Priem, D. On the characteristics of electromagnetic welds between aluminium and other metals and alloys. Weld. World 2005, 49, 74-84. [CrossRef]

19. Zhao, Y.Y.; Li, D.; Zhang, Y.S. Effect of welding energy on interface zone of Al-Cu ultrasonic welded joint. Sci. Technol. Weld. Join. 2013, 18, 354-360. [CrossRef] 
20. Bergmann, J.P.; Regensburg, A.; Schürer, R.; Petzoldt, F.; Herb, A. Effect of the interface characteristics on the joint properties and diffusion mechanisms during ultrasonic metal welding of $\mathrm{Al} / \mathrm{Cu}$. Weld. World 2017, 61, 499-506. [CrossRef]

21. Bisadi, H.; Tavakoli, A.; Tour Sangsaraki, M.; Tour Sangsaraki, M. The influences of rotational and welding speeds on microstructures and mechanical properties of friction stir welded Al5083 and commercially pure copper sheets lap joints. Mater. Des. 2013, 43, 80-88. [CrossRef]

22. Gould, J.E. Mechanisms of Bonding for Solid-State Welding Processes. Weld. Fundam. Process. 2011, 6A, 1-8.

23. Wanjara, P.; Dalgaard, E.; Trigo, G.; Mandache, C.; Comeau, G.; Jonas, J.J. Linear friction welding of Al-Cu: Part 1-Process evaluation. Can. J. Met. Mater. Sci. 2011, 50, 350-359. [CrossRef]

24. Wei, A.; Li, J.; Xiong, J.; Zhang, F. Investigation of interdiffusion and intermetallic compounds in Al-Cu joint produced by continuous drive friction welding. Eng. Sci. Technol. 2016, 19, 90-95. [CrossRef]

25. Lee, W.B.; Bang, K.S.; Jung, S.B. Effects of intermetallic compound on the electrical and mechanical properties of friction welded $\mathrm{Cu} / \mathrm{Al}$ bimetallic joints during annealing. J. Alloys Compd. 2005, 390, 212-219. [CrossRef]

26. Bhamji, I.; Moat, R.J.; Preuss, M.; Threadgrill, P.L.; Addison, A.C.; Peel, M.J. Linear friction welding of aluminium to copper. Sci. Technol. Weld. Join. 2012, 17, 314-320. [CrossRef]

27. Xue, P.; Xiao, B.L.; Wang, D.; Ma, Z.Y. Enhanced mechanical properties of friction stir welded dissimilar Al-Cu joint by intermetallic compounds. Mater. Sci. Eng. 2010, 527, 5723-5727. [CrossRef]

28. Galvão, I.; Verdera, D.; Gesto, D.; Loureiro, A.; Rodrigues, D.M. Influence of aluminium alloy type on dissimilar friction stir lap welding of aluminium to copper. J. Mater. Process. Technol. 2013, 213, 1920-1928. [CrossRef]

29. Akbari, M.; Behnagh, R.A.; Dadvand, A. Effect of materials position on friction stir lap welding of $\mathrm{Al}$ to $\mathrm{Cu}$. Sci. Technol. Weld. Join. 2012, 17, 581-588. [CrossRef]

30. Saeid, T.; Abdollah-Zadeh, A.; Sazgari, B. Weldability and mechanical properties of dissimilar aluminum-copper lap joints made by friction stir welding. J. Alloys Compd. 2010, 490, 652-655. [CrossRef]

31. Schürer, R.; Weigl, M.; Döhner, J.; Bergmann, J.P. Robotergestütztes Rührreibschweißen als Flexible Lösung in der Modernen Fertigung; DVS Congress: Nürnberg, Germany, 2015.

32. Firouzdor, V.; Kou, S. Al-to-Cu Friction Stir Lap Welding. Met. Mater. Trans. A 2012, 43, 303-315. [CrossRef]

33. Martin, J.P. Stationary shoulder friction stir welding. In Proceedings of the 1st International Joint Symposium on Joining and Welding, Osaka, Japan, 6-8 November 2013; p. 477.

34. Bergmann, J.P.; Regensburg, A.; Schürer, R.; Weigl, M. Potentials in robotic Friction Stir Welding using stationary shoulder concepts. In Proceedings of the 11th International Symposium on Friction Stir Welding, Cambridge, UK, 17-19 May 2016. 